\title{
Occupational Health And Safety (OHS) management for employees on the risk of diseases due to the intensity of computer use in the workplace/industry
}

\author{
Andika Bagus Nur Rahma Putra ${ }^{1,}$, M. Ihwanudin ${ }^{1}$, Erwin Komara Mindarta ${ }^{1}$, Poppy Puspitasari ${ }^{1}$, . \\ Mirza Abdillah Pratama ${ }^{2}$ \\ ${ }^{1}$ Mechanical Engineering, Faculty of Engineering, Universitas Negeri Malang, 65145 Malang, Indonesia \\ ${ }^{2}$ Civil Engineering, Faculty of Engineering, Universitas Negeri Malang, 65145 Malang, Indonesia
}

\begin{abstract}
The research objectives of this study are: (1) urgent problems faced by employees when using computers; (2) computer components at risk of causing physical illness; and (3) mapping of disease experienced by OHS related employees on the computer. The subjects of this study are employees in three places of work / industry how many in Malang that work with computers with a duration of at least nine hours per day. The results of this study include: 1) the urgent problems experienced by the employees of the computer user include comfort (60\%), position / feet distance $(60 \%)$, monitor position at the work table (55\%), mouse position (55\%), (70\%), rest breaks $(75 \%)$, sitting position (70\%), work desk condition (15\%), room condition (25\%), and rest break time (35\%); 2$)$ components on the computer that are at risk of causing computer-related OHS diseases that are computer CPU box (5\%), computer monitor (25\%), computer keyboard (10\%), computer mouse (20\%), computer cables ( $10 \%)$, and computer desk-chairs $(30 \%)$; and 3 ) high-risk diseases suffered by employees of computer users include sicca-syndrome $(55 \%)$, astenopia (70\%), headache-comp (85\%), Repetitive Strain Injuries (RSI) syndrom (55\%), and Carpal tunnel syndrome (30\%).
\end{abstract}

\section{Introduction}

Occupational Safety and Health (OHS) has an integral part of the labor and human resources system [1]-[3]. Occupational safety and health are not only very important in improving the social security and welfare of its workers but far from it, occupational safety and health have a positive impact on the sustainability of its work productivity. Therefore, the issue of occupational safety and health at this time is not just an obligation that must be considered by the workers, but also must be met by a system of work [4], [5]. In other words, current safety and health is not merely a liability, but it is a necessity for every worker and for every form of work activity. Occupational health describes occupational health efforts held at each workplace. In particular workplaces that have a great health hazard for workers, OHS is essential in order to work in a healthy manner without endangering oneself and the surrounding community. It is important to obtain optimal work productivity, in line with the labor protection program. Occupational Health and Safety (OHS) is the first aspect to be considered in every work, including when working with a computer. The results revealed that working with

\footnotetext{
* Corresponding author: andika.bagus.ft@um.ac.id
} 
computers can lead to health and even safety disorders. Computers are communication and information technology devices that are often used today, because computers can do almost anything related to communication and information technology [2], [3].

The use of computers without regard to OHS will cause many disturbances to the body parts and body systems [6], [7]. Especially about sitting position when working with computers with a long time and continuously. Some studies suggest that if the condition persists, it can cause suppression of the spinal cord that causes the nucleus pulpous hernia, the spinal cord sandwiched between the two vertebrae [8]. As a result, in addition to low back pain, a sense of tingling will spread from the leg to the foot. In fact, when severe, it can cause paralysis. In addition, the wrong position can cause the risk of interference with Computer Vision Syndrome (CVS), a health problem due to lingering computer use [9]. Complaints include tired and dry eyes, headache, nausea, and vomiting. Computer vision syndrome is not so long ago. The new American Optometry Association suspected this disturbance around the 1990s. In that year, the use of computers began to bloom and complaints surrounding eye fatigue added a lot. It is estimated that about 60 million Americans suffer from CVS. Several studies of schoolchildren in Scandinavia revealed that of 41.6 percent of pupils who suffered low back pain while sitting in the classroom, 30 percent of them sat for an hour, and 70 percent more than an hour. Thus, the risk of tense muscles and other symptoms can be avoided. This research reveals safety and health by working with computers. In addition, we will discuss dangerous risks in computer [4], [10], [11].

\section{Research Method}

This research method is qualitative with survey, multi case, and action research. This method is chosen according to the purpose of research that is (1) urgent problem faced by employees when using computer; (2) computer components at risk of causing physical illness; and (3) mapping of disease experienced by OHS related employees on the computer. The subjects of this study are employees in three working places/industry how many in the city of Malang working with computers with a duration of at least nine hours per day. The research instrument uses semi-structured questionnaire stuffing, in-depth interviews and documentation. Furthermore, the research stages are presented in Figure 1.

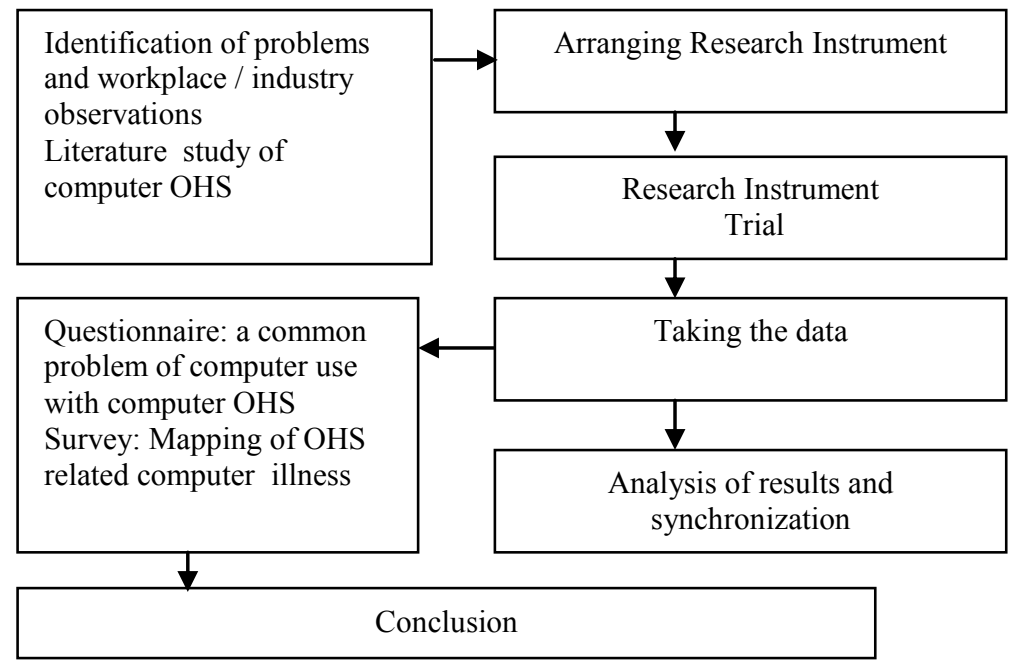

Fig. 1. Research Design Plan. 


\section{Result and Discussion}

\subsection{Employee urgent issues related to computer OHS}

The result of the discussion of urgent problems of employees related to computer use OHS was obtained using survey with questionnaires. The result is then processed by giving a large percentage value. The results are shown in Figure 2.

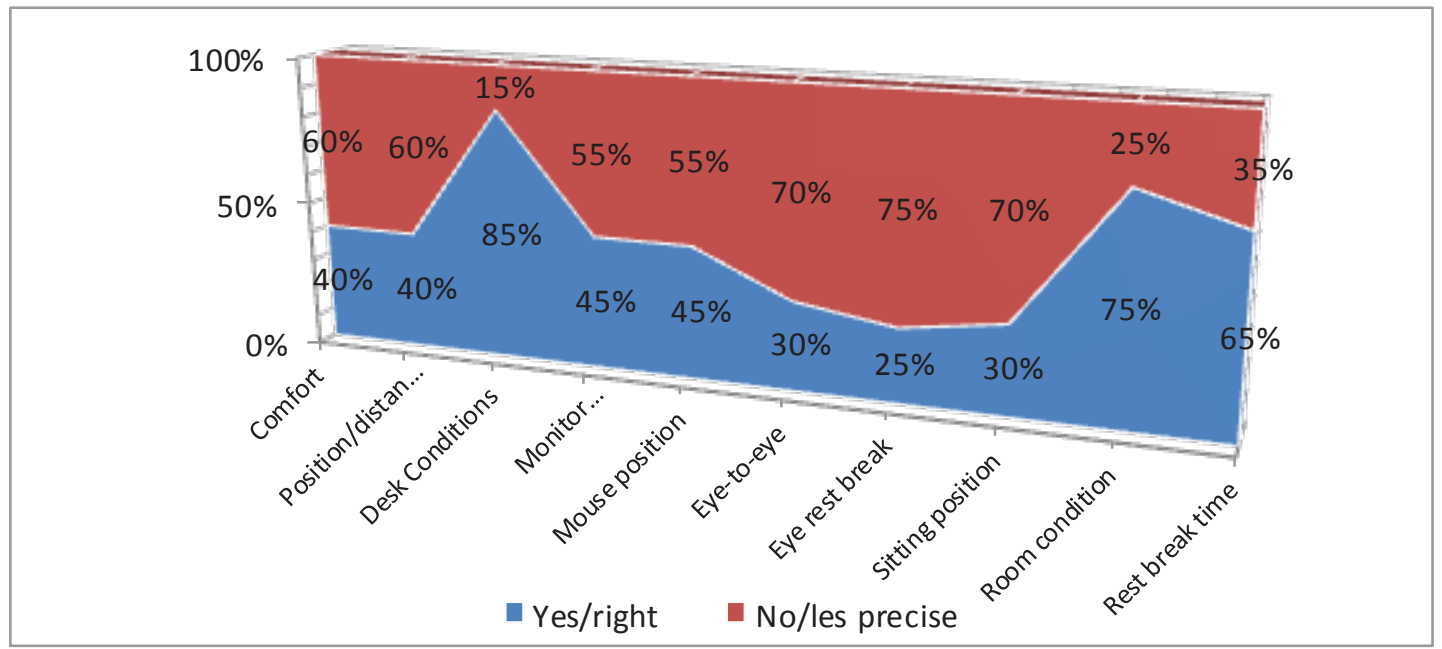

Fig. 2. Percentage of types of employees' urgent issues related to computer OHS

In Figure 2 above, it can be interpreted that there are ten urgent problems faced by OHS related employees on the computer. These issues include comfort, position / leg distance, work desk condition, monitor position on the work table, mouse position, monitor distance to eye, eye break rest, sitting position, room condition, and office break duration. Of the ten problems, there are seven problems that have a percentage above $50 \%$. These problems include comfort $(60 \%)$, position / distance of feet $(60 \%)$, monitor position at the work table $(55 \%)$, mouse position $(55 \%)$, eye-to-eye distance $(70 \%)$, eye rest break $(75 \%)$, and sitting position $(70 \%)$. Furthermore, there are three problems that have a percentage below 50\%. These problems include working desk conditions (15\%), room condition (25\%), and rest break time (35\%).

Based on these results, it can be seen that the problem of lack of time to rest the eyes is the biggest problem (75\%). It becomes a major cause of problems with OHS-related disorders in computers [1], [6]. Lack of time for the eyes to rest can cause various diseases. The eye is one of the most sensitive and vulnerable parts of the disease from outside [2], [10]. Other results indicate that the distance of the monitor to the eye and sitting position also as the main cause of OHS related diseases on the computer. The distance of the legs with the chair and the work table should be appropriate so that the muscles of the legs and knees can be relaxed [9], [12]. especially working in a relatively long time at work. Leg distance is the most vital part that often experience interference and is the most symptomatic effects of disease symptoms suffered by computer users. Monitor distance must be standardized so that the eye is able to focus on the object well. Some experts claim that the correct sitting position should be in accordance with a person's height and weight. Things to avoid in order to avoid lower back pain, among others, do not sit on a chair that is too high or low, sitting with bend the waist, or sitting without a backrest at the lower waist. This is important because the sitting position affects the body's development and blood metabolism in the body [3], [11], [13]. 


\subsection{Computer components at risk of causing computer-related OHS diseases}

Results from the discussion of computer components at risk of causing the associated illnesses of computer use OHS obtained using a questionnaire. The result is then processed by giving a large percentage value. The results are shown in Figure 3.

The specifications presented in Table 2 are the main specifications of coconut harvesting drones. The main components used, all of which are selected by weight, price, and durability. Next, the dimensions of each component of the drone are shown in Figure 3.

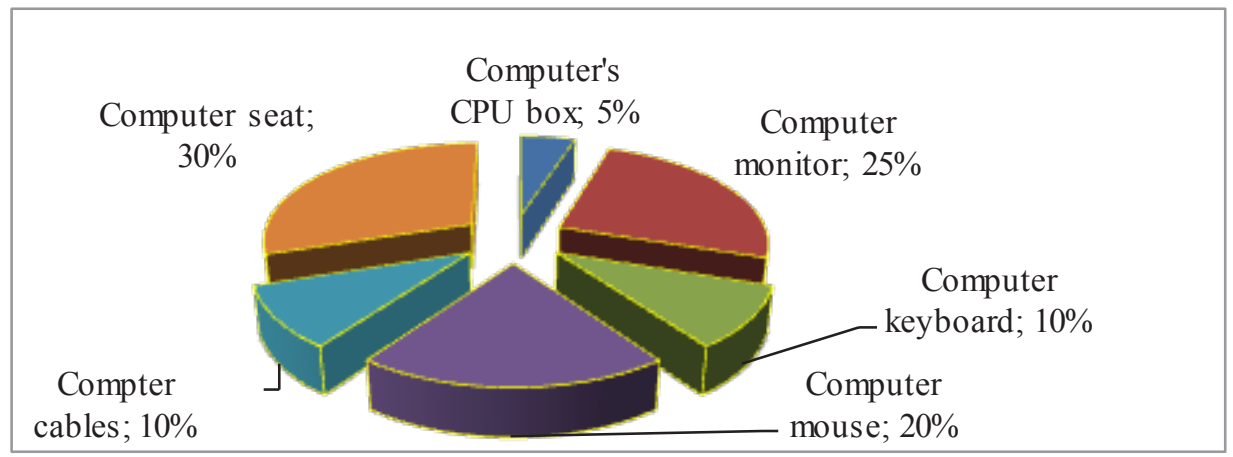

Fig. 3. Percentage of computer components at risk of interference.

In Figure 3 above, it can be interpreted that there are six major components on the computer that are at greatest risk of causing a computer-related OHS illness. Such components include computer casing boxes, computer monitors, computer keyboards, computer mice, computer cables, and computer desks. The percentage of each component is the computer's CPU box (5\%), computer monitor $(25 \%)$, computer keyboard (10\%), computer mouse $(20 \%)$, computer cables $(10 \%)$, computer seat $(30 \%)$.

From the results of the analysis, the component that has the largest percentage value is the deskchair computer. Computer desks are the most risky component because they are the body's main foundation while working [4], [14]. Computer desks and chairs are closely related to the sitting position and comfort of computer users. Unfavorable desks and computer chairs (not ergonomic) can cause rapid fatigue. The desk-chair of the computer needs to be equipped with a foot rest. In addition, the bottom of the table provides free movement space for the feet. On a computer desk-chair, the height of the table is set better around $55-75 \mathrm{~cm}$ (adjusted to the size of the seat and also adjusted to the height of the operator. Another important point is the location of the monitor and mouse can cause aches and pains in the hand [1], [14]. The correct mouse position is next to the keyboard. It needs to be customized hands used to work. Some studies explain that such as working with the left hand, the mouse needs to be placed to the left of the keyboard and arranged for the setting the mouse becomes left handed through the operating system.

\subsection{Risks of illness suffered by employees related to computer OHS}

The results from the discussion of computer components at risk of causing the associated illnesses of computer use OHS obtained using a questionnaire. The result is then processed by giving a large percentage value. The results are shown in Figure 4. 


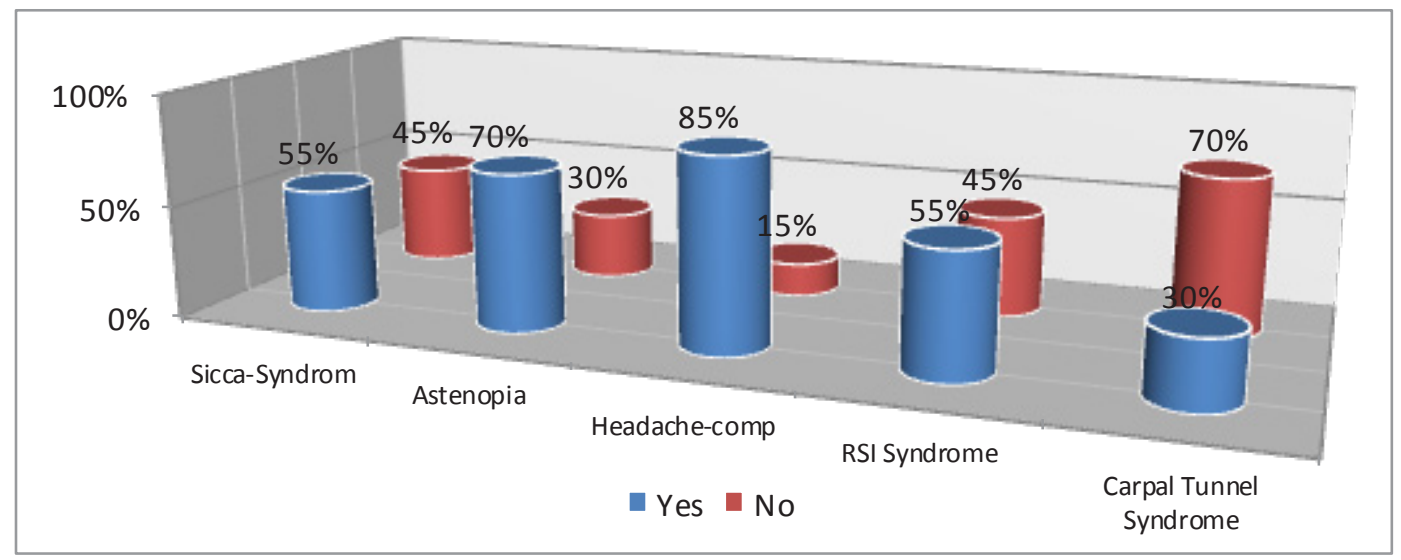

Fig. 4. Percentage of risk of illness suffered by employees related to computer OHS

In Figure 4 above, it can be interpreted that there are five disease risks that can be suffered by employees related to computer OHS. These diseases include sicca-syndrome, asthenopia, headachecomp, Repetitive Strain Injuries (RSI) syndromes, and Carpal tunnel syndrome (CTS). Significant percentage of risk is sicca-syndrom 55\%, astenopia 70\%, headache-comp 85\%, Repetitive Strain Injuries (RSI) syndrom 55\%, and Carpal tunnel syndrome (CTS) 30\%.

The results showed that the greatest percentage occurred in headache-comp disease resicons $(85 \%)$. This disease is a disease with tenderness of muscle tension headache and is the most common type [2], [15]. This disease has symptoms of headaches on both sides of the head, it is suppressing, sometimes feels heavy with constant dull pain. Some studies say that using a relatively old computer will cause the disease is difficult to cure. headache-comp attacks the front, side, or back of the head, but are generally bilateral (both sides). This type of headache is caused by the muscles around the head that contract or strain due to too much focus on the computer [10], [12], [16]. Another cause, because the position of the body that is not moving much, or being in a particular position is too long, or too much reading, working in front of the computer, and thinking too much. Several other disease risks also need to watch out for and soon be solved in a complex. It is important that in working process can be healthier.

\section{Conclusion}

Based on the above discussion, it can be taken some conclusions from this study. The conclusions are described as follows.

1. The urgent problems experienced by the employees of the computer users include comfort $(60 \%)$, position/distance of feet $(60 \%)$, monitor position at the work table $(55 \%)$, mouse position $(55 \%)$, monitor distance to eye $(70 \%)$, rest breaks $(75 \%)$, sitting position $(70 \%)$, working desk condition (15\%), room condition (25\%), and rest break time (35\%).

2. Components on computers that are at risk of causing computer-related OHS diseases are computer CPU box (5\%), computer monitor (25\%), computer keyboard (10\%), computer mouse $(20 \%)$, computer cables ( $10 \%)$, and computer desk-chairs $(30 \%)$.

3. Disease that is high risk suffered by employees of computer users include sicca-syndrom by $55 \%$, astenopia by $70 \%, 85 \%$ 85\% headache-comp., Repetitive Strain Injuries (RSI) syndrom $55 \%$, and Carpal tunnel syndrome (CTS) of $30 \%$. 


\section{References}

1. J. Howard, Am. J. Ind. Med., 10, 1-10 (2017)

2. A. Cooklin, N. Joss, E. Husser, and B. Oldenburg, Am. J. Heal. Promot., 31, 5 (2017)

3. T. K. Peckham, M. G. Baker, J. E. Camp, J. D. Kaufman, and N. S. Seixas, Ann. Occup. Hyg., 61, 1 (2017)

4. G. T. Ognibene, W. Torres, R. Von Eyben, and K. C. Horst, J. Occup. Environ. Med., 58, 3 (2016)

5. G. Garrett, M. Benden, R. Mehta, A. Pickens, S. C. Peres, and H. Zhao, IIE Trans. Occup. Ergon. Hum. Factors, 4, 2-3 (2016)

6. D. Bisht and R. Bakhshi, J. Appl. Nat. Sci., 10, 1 (2018)

7. A. B. N. R. Putra, W. Irdianto, A. Mukhadis, and S. Suhartadi, AIP Conf. Proc., 1778, (2016)

8. A. B. N. R. Putra, A. Mukhadis, and S. Suhartadi, Teknol. dan Kejuru., 38, 2 (2016)

9. M. N. A. Rahman, I. Masood, N. F. Awalludin, and M. F. Hassan, Int. J. Appl. Eng. Res., 12, 7, (2017)

10. N. S. Varsha and P. K. P, Int. J. Adv. Sci. Res. Eng., 4, 2 (2018)

11. E. H. C. Woo, P. White, and C. W. K. Lai, Ergonomics, 59, 3, (2016)

12. S. Nahar and A. Sayed, Int. J. Adv. Res. Comput. Sci., 9, 2 (2018)

13. J. Wahlström, Occup. Med. (Chic. Ill)., 55, 3 (2005)

14. M. S. Sirajudeen, H. Muthusamy, M. Alqahtani, and M. Waly, Biomed. Res., 29, 11 (2018)

15. F. Jusoh and M. N. O. Zahid, IOP Conf. Ser. Mater. Sci. Eng., 319, 1 (2018)

16. M. Osama, S. Ali, and R. J. Malik, J. Pak. Med. Assoc., 68, 4 (2018) 